\title{
Using Interviewing to Explore Clinical Learning at Team Placements:
}

\author{
A Pilot Study \\ Lili Gao \\ School of Foreign Language and Literature, Wuhan University \\ Wuhan, 430072, P. R. China \\ Tel: 86-276-876-5002Ｅ-mail: lilgao@yahoo.com
}

Received: August 23, 2011

doi:10.5430/wje.v2n3p66
Accepted: October 5, 2011

Published: June 15, 2012

\begin{abstract}
This paper reports the development of a pilot study which aims to identify a medical student's experience and perceptions towards team placement learning and how closely those experience and perceptions link to the author's main project--a longitudinal, multiple-method case study, which is designed to investigate how medical students learn in a multiprofessional clinical context, and how multi- and inter-professional contact influences the transition from 'thinking as a student', to 'thinking like a doctor', to 'thinking as a doctor', as an issue of identity construction. By using a reflexive account, the author delineates the strengths and limitations; practicalities and difficulties of in-depth interviewing, one of the qualitative data collection methods to be use in her further study.
\end{abstract}

Keywords: Interviewing, Clinical learning, Team placement, Pilot study

\section{Introduction}

One of the most significant changes taken place in health care setting is interprofessional practice: a dynamic and complex terrain (Irvine et al., 2004) where there is a need of interprofessional collaboration and good team work. The shift in medical practice from uniprofessional settings to multiprofessional settings requires medical professionals to interact closely with members of the healthcare team, and it also brings great challenges to medical education. For medical students, entering such an interprofessional community of practice, they are entering a new multicultural classroom (Kozulin, 2006). Literature has suggested that such learning is best achieved through structured practice placements in mature teams, involving feedback, rather than through shared learning as classroom activity. However, learning in multiprofessional teams, typically involving education in attitudes, communication and shared practices (Bleakley \& Rees, 2005, personal communication), also could be an experience of pleasure or frustration. Literature needs to address important questions such as

(a) How do medical students learn to think, perform and act like a professional in medical team placements?

(b) What are the students' perspectives and experiences of learning within the team?

(c) What strengths and weaknesses may be identified?

(d) What are the common struggles and transitions that students may encounter in the identity construction, and who/what factors influence each developmental stage: from 'thinking like a student' to 'thinking like a doctor', to 'thinking as a doctor?

Those qualitative questions can be best examined qualitatively, since qualitative paradigm focuses on understanding and describing the world of human experience based on the viewpoint of respondents through detailed descriptions of their cognitive and symbolic actions, and through the richness of meaning associated with observable behavior (Myers, 2000). 


\section{Study Design}

One important methodological option in conducting qualitative research is the use of qualitative interviewing for data collection and analysis. Qualitative interviewing, according to Gaskell (2000) can be interviews of a semi-structured type with a single respondent (in-depth interview) and a group of respondents (focus group). Methodologically, I chose in-depth interview rather than focus group for this pilot study. First, taking the pragmatic consideration, I will have difficulties in recruiting a group of medical students before my ethical application is approved. Second, research interview is a social process, in which words are the main medium of exchange (Gaskell, 2000). So, strategically, it will be easier for me to conduct in-depth interview, a one-to-one conversation, even though focus groups are ideal for exploring people's experiences, opinions and beliefs (Kitzinger, 2005).

Talking to people can be easy, but interviewing is "an art and science requiring skill, sensitivity, concentration, interpersonal understanding, insight, mental acuity, and discipline" (Patton, 1987, p.108). According to Patton, there are three basic approaches to collect qualitative data through in-depth interview: the informal conversational interview, the general interview guide approach and the standardized open-ended interview. Each of the three approaches serves different purposes and involves different types of preparation, conceptualization and instrumentation. The interview guide approach was used for this pilot study and an interview guide possessing five topics areas was generated with reference to Patton's six types of questions for qualitative interview. The interview guide was to act as a basic checklist to cover all the relevant topics by using the limited time in interview.

\section{Data Collection Methods}

\subsection{Sampling: a frustrating experience}

Connected with the research setting and study population of my main project, purposive sampling had been planned to recruit one or two Year 3 or 4 medical student(s) from the new medical school in the south west of England, which lends itself to my research questions. The school has emphasized innovative curriculum for developing in students 'thinking as a doctor'--- the convergence of clinical reasoning skills, professional attributes and behaviours from an early stage. According to its curriculum, Year 3 and 4 students involves extensive exposure to the clinical environment under an innovative programme known as 'Pathways of Care', through which students experience first hand how the NHS works as a team to deliver patient care. When experiencing the multi-professional nature of health care, they could learn with and from other experts in the health care community, thus the formation of their professional identity in this multicultural classroom could be affected.

On the basis of accessibility and convenience, I came to the Public Health Library where I have been 'immersed' in the day-to-day-lives of medical students. It seemed that grabbing one or two medical student(s) to ask some questions was so simple and straightforward to me. I assumed that I was ready to go any minute with a tape recorder. However, my challenge came. The excerpt from my Field Notes illustrated my frustrating experience of locating interviewees,

....all of them absorbed in doing their work. No chance to say hello to anyone. Should I target those who looked bored? Typing! No bored one... One hour, two hours passed. How silly to come to IT suite to locate an interviewee! Go to the Café downstairs... There came in a female student. Sat opposite to me, a good chance to say hello, but she took out her cell phone and kept on chatting until she left me behind...A male student with a big backpack. Didn't go to the Fine Filling. Walked to the deep corner of this hall. Sat at the corner, buried his head in a newspaper--- "don't bother me??"...Two male students walked in side by side, to the Reception Desk next to the Fine Filling. Talked with the receptionist, disappeared into the Student Common Room. Two girls giggled in, wearing black coats and skirts. Sat at the table on my left, eating their lunch, chatting and laughing. No, absolutely "immoral" to spoiling this sweetest moment of girls' private conversations...Drinking my coffee, the 2nd cup [never like this bitter 'medicine', but that's the culture] ... Finally, a chance to approach to a student, "I am a research student of medical education.." "Ah, research?" A questioning look. Her peer came and off she left... "NMS students? Had better not bother them now..." Kind and concerning suggestions. Still waiting for the ethics approval. Thinking about my 'future', I'd better stop here... (Field Note, August /2007).

My original plan to interview medical students to obtain their views and experiences came into an abortion. I abandoned my attempt to collect data on medical students' perspectives as Bowler (1997) had to give up collecting her data from South Asian women's perspectives and experience of maternity service. "None of the women I had contact with wanted to discuss these topics with me...," she reflected her failure "stem from the fact that the notion of research and its methodologies and philosophies are structured by culture: that is, that the concept of research has risen from Western culture and thought" (p.73). And my difficulties, in retrospect, stemmed from lack of courage and confidence to approach to my potential participants, a group of young white medical students. There raised a question of that my 
ethnicity (an Asian) might be a barrier in my research in the future. To get into medical students' community and to bridge racial and ethnic barriers can be a methodological challenge in my further study. In addition, ethical issues have been in my thoughts before I have 'that piece of paper' from the school Ethics Committee.

Finally, convenience sampling was used to recruit a staff remember, J, who had been trained as a medical student. A formal email letter was sent with explanation of the purpose of this pilot study. A convenient date, time and location were arranged for the interview by email.

\subsection{Interviewing: an enjoyable process}

Following Litchman's (2006) five main components of interviews, I had a small talk with J at the opening of the interview. I informed him again of the purpose of this interview, the issues of anonymity and got his consent to be audio taped. Before we began, I invited him to ask any questions he'd like to ask me about this interview and thanked him for his time. The whole interviewing process was quite enjoyable. It took 50 minutes, longer than I had planned. With my previous experience of being a teacher, I felt quite skilled in handling asking questions, navigating the topics, listening actively while remaining aware of the conversation process. On the other hand, J, as an open-minded intellectual, was very active in responding all my enquiries. At the end of the interview, I asked him if there was anything he could tell me about my topic of inquiry which I had missed, he informed me of some additional areas I hadn't anticipated: about his experiences in the team after his undergraduate training and his opinions about medical education. Bowler's (1997) descriptions echoed what I have experienced in interviewing J: “....interview depends upon the active participation of the research subject, who needs to share the general objectives of the research and so provide information or articulate views and opinions" (p.70).

\section{Data Analysis Procedure}

\subsection{Transcribing: a sweet bitterness}

The interview was transcribed fully (verbatim) overnight while it was still fresh in my mind. As Maykut and Morehouse (1994) note that words are the data of qualitative research, I think it is very important to transcribe the taped interview carefully and completely. The more I listened to the tape, the more familiar I got with the data. While transcribing, I also realized I need to improve my interviewing strategies. For example, I could hear myself on the tape giving too much yes or $u h$-huh. I was happy to be engaged in the natural conversation with $\mathrm{J}$, but too much of my response had created problems in transcribing, which must be avoided in my future work. Later, as I read Seidman (1998), I found out that there was another risk in giving too much of those affirmative responses, which could distort how the participant responds, although such reinforcement calls attention, showing that the interviewer is listening and being attentive. Listening is the most important skill in interviewing, however, as Seidman (1998) points out that "the hardest work for most interviewers is to keep quite and to listen actively" (p.63). Another problem was that I had cut in J's talking several times and even interpreted his saying. My teaching experience had again unconsciously made me lead the conversation. In my future study, I will try not to interrupt interviewees when they are talking and I can "jot down the key word and follow up on it later", an approach termed as 'the echo' by Richardson et al. (1965) (cited Seidman, 1998, p.70).

After finishing transcribing, I contacted $\mathrm{J}$ and thanked him for being interviewed. Transcribing, time consuming and daunting, but was worth doing it by my own---a process of sweet bitterness.

\subsection{Organizing interviewing text: a three step strategy}

Whenever comes to qualitative data analysis, those words are most commonly used to describe the attributes of qualitative data: messy, complex, cumbersome, large amount, enormous quantity, unstructured, daunting. In a recent article (Thorne, 2000), it was stated that qualitative data analysis is "the most complex and mysterious of all of the phases of a qualitative project, and the one that receives the least thoughtful discussion in the literature" (p.68). Indeed, literature writes the process of data analysis quite vague and ambiguous, which often concludes: no gold standard, not a liner process, no right way to do, no agreed-upon ways of analysing, few universal rules, and so on.

With pages of interview text on my desk, I asked myself where my philosophical position is towards qualitative interviewing data analysis. I believe there is an interconnected relationship among research questions, data collection methods and topic areas used in interviewing. I also believe that I am the best to make sense of my data rather than anyone else. As Lichtman (2005) says, "The hard work of sifting, sorting, coding, organizing, and extracting remains yours" (p.166). A good qualitative researcher should be a critical thinker, and I think he or she also should be a good organizer in managing the 'messy' data.

Before I went into the data analysis process, I used a concept map to show the particular interconnected relationship within my study. I found out that the categories/ themes had already been established in advance in my interview guide, 
therefore what I needed to do now was to read and re-read the interview text, to highlight my interviewee's response to those topics, to create a new list of categories: clinical difficulties; experience at team placements; how to learn; what to learn; roles and additional ideas.

Then I opened a new word document named Matrix of Concepts from J, using the cut-and-paste method (Maykut \& Morehouse, 1994) to put J's responses into each category: a step of moving from categories into concepts or themes, which is called as 'fracture the data' (Strauss, 1987) and 'data reduction' (Marshall \& Rossman, 1995). Work of this stage is often suggested to be done by using computer software programmes such as NUDIST, Nvivo, which can reduce my date quickly to some manageable form. However, my research questions CAN'T simply be answered by re-arranging data into categories. It is important to remember Leavis's argument that "analysis is not a dissection of something that is already and passively there", but "a constructive or creative process" or "a more deliberate following-through of the process of creation" in response to "the words on the page" (Storer, 2009, p.87).

\subsection{Using content analysis}

Basically, there are four types of analysis of qualitative interviewing: content analysis, thematic analysis, critical analysis and theoretical analysis. Any analysis is decided by our research questions and other factors such as study purposes. For this pilot study, I did a simple content analysis or textual analysis. In order to obtain a comprehensive view of the information I had had from him, I read and reread Matrix of Concepts from J, especially paying attention to some words he had used so frequently in the interview such as "difficulties", and some synonyms he had used such as "doing, participating". Then I used a diagram to summarise a conceptualization and understanding of his experiences and perceptions towards clinical team placement learning before I built a valid argument for this study.

\section{Discussions}

\subsection{General findings}

There are some significant general findings derived from this pilot study. For a medical student, clinical experience is a vital and difficult part of the undergraduate course. Learning by observing and doing within a real and a broader context, he is confronted with all of the physical, emotional, and clinical difficulties. By moving all those difficulties from Year 3 to Year 4 in his medical educational process, the medical student is moving from being a student to thinking and doing things in the same manner as a doctor: from "swimming in the sea and drowning" to an "Ah-ah experience"(J, personal communication, 2006). He develops theoretical knowledge, practical reasoning skills and clinical responsibility by working within his team, which leads to formation into the practices of a doctor. However, the medical student taught under the traditional curriculum has little chance to be involved in mutlprofessional team placements such as an A and $\mathrm{E}$ department since there is not much crossover between health care professionals. This calls further research to study those who are now taught under the new curriculum, focusing on clinical learning within complex and dynamic team placements.

\subsection{Strengths and weakness of this study}

One of the strengths of this study is that in-depth interview has provided me with rich data of J's experience as a medical student, his own framework of the meaning of such learning and his perspectives towards clinical education. J's experiences of being taught as a medical student, of teaching medical students, of seeing things in comparative perspectives have offered me a provoking insight into the research topic of my main project.

Another strength is that the flexibility of in-depth interview allows me to have additional information beyond my topic of enquiry. J's views about the school's third and fourth year education are out of my anticipation, but have obviously raised a new question to my main project: do I really need to do a large scaled pilot study to test my research setting?

Weaknesses do exist in this pilot study. First, the person I interviewed is not the one that I had planned to. What I have got from him can be different from what I will get from a student. J finished his medical training a long time ago, and what he can tell me is what he can recall from his long-term memory. People tend to 'select' to remember what has been most significant for them while dropping out the tedious and boring parts of their experience. It can be those 'forgotten bits' that make sensible data to me in my further study.

Another weakness is that I could only interviewed one informant because of time limitation for this pilot study. Therefore it is impossible for me to do inter-analysis between interviews or to use multiple qualitative methods to explore my research questions further. Another point has to be acknowledged that the interviewee and I know each other and the relationship between us is a potential source of bias. 


\section{Implications}

6.1 Qualitative research often involves ethical issues and as a novice researcher, I am still struggling with ethical codes in doing qualitative research. The question remains open of that in qualitative research to what extent we are not against ethics when we researchers talk to people or observe what they are doing. While preparing for a consent form of ethical application for my main project, I know what I have put in the form won't cover what will happen to my participants in the field. The characteristics of complexity and unpredictability in qualitative research have suggested that it is unrealistic to design a study that can predict or avoid every potential ethical issue in advance. Neither have specific rules for ethical considerations been offered in literature. However, I believe that, as a researcher, I should have a common sense and moral responsibility to reflect upon my own role, my position both inside and outside the field, the potential ethical risks to participants in the course of my study and upon how those potential risks can be reduced to a minimum. At this point, I quite agree on Lichtman's (2006) argument, "Researchers observe not only participants but also themselves, which allows them to documents how they presence affects the research process and its products. As individuals we are the determiner and judge of our own behaviours. All the guidelines and regulations are only that; ultimately, how we behave is our own person responsibility" (p.58).

6.2 At a pragmatic level, we researchers have to be aware of how different kinds of data we can get by interviewing a different stakeholder, even within the same group of stakeholders. We have a vast range of stakeholders related to our investigation, thus, our research findings can be partial.

6.3 Interviewing is a flexible and powerful tool (Britten, 2000) to understand the phenomenon of interest, but the employment of multiple methods in data collection and analysis will definitely increase the trustworthiness of our findings, for example, the combination of interviews, observations from the field and reviewing relevant documents; building an audit trail; using member checks and working with a research team.

\section{References}

Bowler, I. (1997). Problems with interviewing: Experiences with service providers and clients. In G. Miller \& R. Dingwall (Eds.), Context \& Method in Qualitative Research (pp.66-76). London: Sage.

Britten, N. (2000). Qualitative interviews in health care research. In C. Pope \& N. Mays (Eds.), Qualitative Research in Health Care (2nd ed) (pp.11-19). London: BMJ Books.

Gaskell, G. (2000). Individual and group interviewing. In M.W. Bauer, \& G. Gaskell (Eds.), Qualitative Researching with Text, Image and Sound A practical Handbook (pp.38-56). CA: Sage.

Irvine, R., Kerridge, I. \& McPhee, J. (2004). Towards a dialogical ethics of interprofessionalism. J Postgrad, 50 (4), 278-80.

Kitzinger, J. (2005). Focus group research: using group dynamics to explore perceptions, experiences and understandings. In I. Holloway (Ed.), Qualitative Research in Health Care (pp.56-69). Milton Keynes: Open University Press.

Kozulin A. (2006). Vygotsky's sociocultural theory and educational problems of $21^{\text {st }}$ century. Seminar: Exeter University.

Lichtman, M. (2006). Qualitative Research in Education, A User's Guide (p.58 \& p.166). CA: Sage.

Marshall, C. \& Rossman, G.B. (1995). Designing Qualitative Research (2nd edition). Thousand Oaks, CA: Sage.

Maykut, P. \& Morehouse, R. (1994). Beginning Qualitative Research: A Philosophic and Practical Guide (p.67). London: The Falmer Press.

Myers, M. (2000). Qualitative research and the generalizability question: standing firm with Proteus. The Qualitative Report [On-line serial], 4(3/4). http://dx.doi.org/10.1177/104973200129118534

Patton, M. (1987). How to Use Qualitative Methods in Evaluation (p.108). CA: Sage.

Storer, R. (2009). F. R. Leavis (p.87). New York: Routlege.

Seidman, I. (1998). Interviewing as Qualitative Research: A Guide for Researchers in Education and the Social Sciences (p.63). New York: Teachers College Press.

Strauss, A. (1987). Qualitative Analysis for Social Scientists. Cambridge: Cambridge University Press.

Thorne, S. (2000). Data analysis in qualitative research. Evidence-Based Nursing. 3(3), 68-70.

http://dx.doi.org/10.1136/ebn.3.3.68 